\title{
Exploring the Overrepresentation of Black Male Students in Special Education: Causes and Recommendations
}

\begin{abstract}
An overrepresentation of Black male students identified as having disabilities is pervasive in American schools. This troubling reality may be the result of disconnects between Black males and their White teachers. Racial differences likely contribute to the high number of Black males referred for programs for students with disabilities. This paper explores the overrepresentation of Black male students identified as having disabilities and recommendations for supporting their success.
\end{abstract}

KEYWORDS: overrepresentation, special education, disability

An overrepresentation of Black male students identified as having disabilities has been pervasive in American schools for decades (Skiba et al., 2016). Compounding this problem is that the majority of American teachers, including teachers for students with disabilities, are White (Cherng \& Halpin, 2016). Overrepresentation as having disabilities occurs when any specific group of students is identified as having disabilities at rates that are disproportionally larger than their representation in the total school population. (Artiles et al., 2010). One reason behind this troubling reality may be disconnects between Black males and their White teachers. Racial differences, cultural differences, and differing behavioral norms likely contribute to the high number of Black males referred for placement in programs for students with disabilities (Gatlin \& Wilson, 2016; Obiakor, Beachum \& Harris, 2010). This paper explores the overrepresentation of Black male students identified as having disabilities and recommendations for supporting their academic success. 


\section{Risks of Inappropriate Identification of Disabilities}

In the United States "special education" refers to specialized instruction utilized to educate students with disabilities. While special education encompasses services to provide academic and emotional supports to students with disabilities, there are risks when students are placed in segregated, restrictive settings away from their peers without disabilities (Artiles et al., 2010; Bean, 2013; Linton, 2015). Artiles et al. (2010) ask if the promises of, and benefits from, special education are actually delivered. For students who are referred for special education, success is measured when supports are in place and when general education inclusion is provided with the appropriate amount of special education support (Gatlin \& Wilson, 2016; Morgan et al., 2017; Obiakor, Beachum \& Harris, 2010). While access to the general education curriculum varies from student to student, the amount of time a student is restricted to segregated special education settings is a hindrance to the student's academic and emotional well-being (Morgan et al., 2017).

Blanchett (2009) puts forth the hypothesis that Black students in the United States are being re-segregated because of their disproportionate placement in special education programs. She contends that students who have little to no exposure to general education curriculum are being placed at a disadvantage compared to their peers without disabilities. Students who spend the majority of their day in special education classrooms miss academic instruction and social interaction in contrast with students who spend their days general education classrooms and are therefore placed at an academic and social-emotional disadvantage (Artiles et al., 2010). Additionally, students placed in segregated special education settings may experience the negative stigma of being in special education and losing the opportunity to experience general education. Special education, for students who are not truly in need of special education services, are at a risk of leaving high school without sufficient skills needed to be successful as an adult and are also at risk of not achieving their potential because of the differences in academic rigor between special education and general education classrooms. Special education is society's response of an individual being different, yet the individual's self-image may begin to reflect this imposed label (Golds \& Richards, 2012; Bean, 2013; Linton, 2015). 


\section{Overrepresentation of Black Male Students}

Educational scholars and stakeholders question whether the overrepresentation of Black males as having disabilities is an issue of misjudging culture, or an issue of racism and a violation of the students' civil rights (Artiles et al., 2010). Racism is theorized to occur in schools when teachers and administrators use special education services to place students into highly restricted settings instead of engaging in targeted attempts to remediate students' academic achievement and/or behaviors that do not conform with behaviors considered acceptable by the school-schools that are staffed by majority White teachers and administrators (Gatlin \& Wilson, 2016; Obiakor, Beachum \& Harris, 2010). Instead of providing effective interventions while the students remain in the general education setting, some teachers may believe that placing students into a restrictive setting will benefit students who are struggling.

Students who look differently, speak differently, and behave differently in comparison with the White, middle-class norms of most schools throughout the United States, are at risk of misidentification as having disabilities and this is especially true for Black males (Ford \& Russo, 2016). Black males are also at risk of inappropriate placement into classes for remedial instruction, and grade level retention may also occur (Talbert-Johnson, 2001; Mandell et al., 2008). Black male students are left disenfranchised, due to a lack of being included in general education practices and may also be disempowered due to limited educational opportunities.

\section{Subjective Referral Processes}

The biases and subjectivity of special education referral assessments are theorized to be linked to factors of misplacement for students of color in special education programs. According to Harry \& Anderson (1994), assessments that are normed on the White majority and that include test items chosen from the cultural experience of this majority are inevitably biased in favor of that majority and therefore biased against minorities, whose cultural experiences are distinctly different (Obiakor, Beachum \& Harris, 2010). Harry \& Anderson (1994) explain that the special education referral process is biased because it places students whose cultural 
and social experiences do not include the kinds of knowledge and skills tested by these instruments at a disadvantage. If special education screenings and referral processes are skewed in favor of the majority-White individuals-being properly assessed for special education services, then students of color are at risk for being misplaced in special education. In simple terms, Black male students may be misplaced in special education because they do not fit White cultural norms. Special education services must reflect a student's need and abilities and if they do not, then the student is not being properly served and the public school system is not meeting the student's needs per federal legislation (Linton, 2015; Gatlin \& Wilson, 2016).

Biases related to clinical judgement may be a factor of inappropriate disability designation. Gatlin and Wilson (2016) explain that the categories in which Black males are more likely to be diagnosed-specific learning disability, mild intellectual disability, and emotional disturbancedepend on clinical judgement which consists of opinions informed by those conducting the assessments. The aforementioned disability categories are determined by the observations of school personnel, clinical judgement, and other standardized and formal measures. However, this is problematic as it is difficult to measure behavioral differences in a truly objective manner. These categories of disability are referred to as socially constructed disabilities because of the subjective nature of their diagnosis as opposed to categories such as visual or hearing impairment whose diagnosis is objective and easily discernable to others. Contrasting the categories visual or hearing impairments, disabilities such as specific learning disability, mild intellectual disability, and emotional disturbance are significantly more dependent on judgement and biases (Obiakor, Beachum \& Harris, 2010). Assessments developed by White individuals may contribute to the risk of Black male students' placement in special education programs (Harry \& Anderson, 1994; Obiakor, Beachum $\&$ Harris, 2010). Likewise, the teacher referring the student for special education services is subject to biases, prejudices, and stereotypes reflective of the school culture-typically White middle-class. In making a referral, teachers who belong to the majority group in society may be influenced by what is considered "normal" based on standards set by White culture. Questions and concerns have understandably been raised regarding possible misidentification of Black males for special education resulting from discriminatory practices, prejudices, or implicit biases (Artiles et al., 2010). 
Cultural differences. Norms in White, middle-class American culture can differ from those from Black culture (Harry \& Anderson, 1994; Talbert-Johnson, 2001). However, it is a larger issue than a cultural difference or a cultural disconnect. Features of Black males' behavioral profile may aggravate White female teachers' negative view of that student population (Harry \& Anderson, 1994). Subsequently, racial prejudice and classification for students with disabilities begins at the initial stage of classroom referral (Woodson \& Harris, 2018).

Black male students may be more frequently referred if general education teachers-again, predominately White and middle class-lack experience and training working with Black students. According to United States federal legislation, prior to making the special education referrals, teachers must attempt other forms of interventions; however, the interventions employed are often punitive: detention, expulsion, or suspension (Obiakor, Beachum \& Harris, 2010). Teachers often prefer students who demonstrate a narrow repertoire of socially acceptable behaviors, academic performance, language, etc. without considering differences of culture, race, or ethnicity (Harry \& Anderson, 1994; Neal et al., 2003). While differences of culture should be celebrated and viewed as opportunities to enhance learning for all, behavior and cultural differences may be viewed as being abnormal, and may lead to students from diverse cultures being inappropriately placed special education programs (Robinson \& Norton, 2019).

The public school system has not functioned as an unbiased system for students of color or cultural backgrounds that differ from White Americans (Irvine, 2012; Bean, 2013), and cultural biases may play an unintentional role in the special education referral process (Mandell et al., 2008; Obiakor, Beachum \& Harris, 2010). To reverse this trend, tools for assessing and diagnosing behavioral disorders such as attention deficit hyperactivity disorder should be screened for cultural bias prior to finalizing the diagnosis (Mandell et al., 2008; Obiakor, Beachum \& Harris, 2010). Educators and administrators must understand and reflect on their own implicit biases, understanding the critical role they play in the special education referral process and the potential detriments on students.

Linton (2015) describes the behaviors of Black male students, how the behaviors differ from White, middle-class norms, and how the behaviors could lead incorrectly to the identification of behavioral disorders. Linton studied behavioral reported from Black male students and parents and how the ratings contrasted the teachers' ratings of the students. While the 
teachers rated Black male students' behavior as being very challenging, the students rated their own behavior as not challenging. This could be interpreted as the students being lenient in their perceptions of their own behavior; however, the parents' behavioral rating scales matched those of their children. These inconsistencies signal that teachers will benefit from an increased awareness of differences in behavioral expectations.

White teachers may, without knowing, may also have a negative predisposed outlook on Black students based on the way they talk and (Obiakor, Beachum \& Harris, 2010). Many Black individuals in America speak a dialect of English-African American Language-that is different than "standard" English typically spoken by White Americans, and patterns of language learning and usage of Black students is often undervalued in schools (Obiakor, Beachum \& Harris, 2010; Robinson \& Norton, 2019). For Black males, their native dialect can be perceived as hostile and threatening according to White school culture. This perception of aggressive language can have a powerful influence on a teacher's opinion: it may lead to a special education referral from the general education teacher. It is imperative that general education teachers, along with special education teachers understand that African American Language has differing semantics and accents, and when large numbers of students are referred to special education for differences in dialect, then that group of students is at risk for experiencing negative outcomes as a result of an inappropriate public education (Irvine, 2012). Differences in dialect may be partnered with differing norms related to externalizing behavior between White and Black individuals. White teachers may not be knowledgeable about cultural norms related to behavior and may misinterpret behavior from black students as aggression, hyperactivity, or defiance, leading to high numbers of referrals to special education (Bean, 2013).

Differences in behavior may be linked to the family income. In the United States, a disproportionate number of Black individuals and families have significantly lower incomes in comparison with White individuals and families, and larger percentage of Black families live in poverty in comparison with White families (Poverty USA, 2020). Living in poverty is associated with decreased neighborhood safety (United States Housing and Urban Development, 2016), which has been linked to externalizing behavior among students (Kim et al., 2019). Additionally, Black students who experience trauma at an early age are more likely to demonstrate challenging externalizing behaviors in comparison with their white peers (Artiles et al., 2010; Bean, 2013; Linton, 2015). Teachers may perceive be- 
havior as challenging from their Black male students and determine that a special education referral is the best course of action rather than seeking other sources of support and or interventions for the student. The cultural differences between Black male students and their White teachers, in combination with the subjectivity of assessments, may result in special education misplacement (Obiakor, Beachum \& Harris, 2010).

Families of Black male students. The parents of Black male students in special education often feel like that they are not aware of the special education processes or the positive impact of special education. Irvine (2012) describes a large set of parents from one school who reported thinking that their children were placed in special education because their students were low achieving. They also reported the belief that their children's teachers were more concerned with the class's over test average rather than with individual student performance. The parents reporting holding a belief that once their students were placed into special education, they were not allowed to leave the program.

Special education teachers as well as general education teachers may have misconceptions about Black parents and the support they provide their children (Irvine, 2012). Teachers who admit to believing in racial stereotypes, especially the belief that academic underachievement is inherently associated with Black males. Such deficit-oriented thinking can make it quite challenging for the parents of Black male students to advocate for their children who are disproportionately represented in special education (Mandell et al., 2008).

\section{Recommendation 1: Culturally Responsive Teaching Practices}

Teachers, typically the individuals to initiate the special education referral process, must become experienced and given specific training regarding culturally responsive academic and behavioral supports and interventions for students from diverse cultures (Linton, 2015; Gatlin \& Wilson, 2016; Woodson \& Harris, 2018). Teachers who are culturally responsive interact frequently with the families about their students' progress (Irvine, 2012). Instead of the teacher independently trying to plan instruction for each student, a culturally responsive teacher learns about the student's culture and environment, then uses that knowledge as one tool to guide their instruction. Group work and group activities support a culturally responsive teaching method. Research suggests that Black male students 
work well during group work activities with carefully constructed learning targets, modeled behavioral expectations, and high expectations. Racial segregation and ethnically homogenous groupings should always be avoided and teachers should allow flexibility and cooperation when developing groups (Irvine, 2012; Morgan et al., 2017).

Teachers must be provided with targeted training in working with diverse students (Irvine, 2012; Alter, Walker \& Landers, 2013). New teachers in particular feel inadequately trained to teach culturally diverse students and to deliver culturally responsive pedagogy. General education teachers play a significant role in the special education referral process; therefore, it is imperative to have teachers who are culturally sensitive and have proper training. White female teachers, who are a majority of America's teaching population, may be unfamiliar with or insensitive toward Black male student experiences (Harry \& Anderson, 1994). Not only should more teachers be properly trained to effectively teach students who are culturally diverse, but they should also receive training on the detrimental effects students experience when they are inappropriately placed in special education (Bean, 2013).

Teachers must familiarize themselves with cultural differences and the understanding that assessment and referral processes are often biased. Patton (1998) explains that inherent in the processes of observing, identifying, and interpreting worth and behavior and reaching a determination of deviance is a culturally bound frame of reference on the part of the observer. Historically, these processes have not displayed an adequate amount of empathetic understanding of, and respect for, 'other.' It must be understood that special education is not always a support system, and according to Blanchett (2009), general education teachers must be provided with targeted training in the use of culturally responsive academic and behavioral interventions prior to requesting special education referrals. Doing so may prevent special education programs being utilized as placement for students who do not truly have disabilities. Likewise, as teachers often report behavioral challenges from Black male students, there is an urgent need for schools to provide adequate training with ongoing in-class modeling and corrective feedback when necessary. Teachers need a plethora of different skills to adequately meet the academic and behavioral needs of students from culturally diverse backgrounds (Talbert-Johnson, 2001).

Communication, collaboration, and reflecting on academic and behavioral supports provided to Black males students in special education are 
all effective support strategies. Positive relationships between teachers and students is important for the success of Black male students (Irvine, 2012). Gatlin and Wilson (2016) found that promoting success paired with collaboration and communication between student, teacher, and parents is one of the most effective ways to help Black students student to succeed. Teacher communication with families and observation of students in their communities and home settings can enhance teachers' understanding of processes that will support diverse students' learning (Irvine, 2012; Gatlin \& Wilson, 2016). Not only does communicating with the student's family help the teacher gain a better understanding of cultural backgrounds, but it also strengthens the relationship between student and teacher, and creating positive relationships is imperative.

\section{Recommendation 2: Recruit Black Teachers}

Recruiting more in higher numbers of Black teachers would effectively support Black male students. Researchers and advocates have frequently noted the imbalance of White female teachers in contrast with diverse student populations (Fish, 2019; Scott, Trainor \& Bettini, 2019). Teachers of color can advocate for students of color and they also have a greater understanding of the culture of diverse students. Schools that have high percentages of teachers of color have lower rates of disciplinary referrals for students of color, and teachers of color perceive unexpected behavior as less problematic than White teachers (Fish, 2019). Black male students who are taught by a teacher of color have higher grades test scores and overall grades. Scott, Trainor and Bettini (2019) found that teachers of color have a better understanding of the behavior of students of color and the students' experiences outside of school, leading to a greater connection and relationship between teacher and student. In order to address the cultural disconnect, Black teachers can bridge the proverbial gap and serve as role models.

Black teachers can positively influence all students as they provide important contributions to the school, enriching both the environment and the curriculum (Talbert-Johnson, 2001; Fish, 2019). More Black teachers would increase the understanding and awareness of the behaviors that often result in Black males being referred for special education. Likewise, Black teachers can advocate for academic and behavioral strategies and interventions for Black students. Increasing the number 
of Black teachers in the United States should not be a dream, but a plausible outcome for providing equality in the public education system (Talbert-Johnson, 2001).

\section{Recommendation 3: Culturally Responsive Screening Practices}

The overrepresentation of Black makes as having disabilities would likely decrease if culturally sensitive screenings and evaluation practices were utilized (Morgan et al., 2017). According to Dizon et al. (2013), school psychologists who are involved in special education referral processes should utilize multiple forms of data prior to determining an eligibility. According to Mandell et al. (2008), in order to create an assessment that is culturally sensitive and standardized, collaboration between mental health and education systems may lead to a more effective approach towards evaluating Black male students for special education services.

\section{Recommendations for Black Males Identified with Disabilities}

Some scholars and other stakeholders theorize that restrictive special education classrooms further segregate and disenfranchise Black males from the school community (Harry \& Anderson, 1994; Artiles et al., 2010; Obiakor, Beachum \& Harris, 2010), and that the risk of being ostracized and restricted from general education curriculum may negatively impact the students (Irvine, 2012; Gatlin \& Wilson, 2016). Black males, if properly assessed and determined to be eligible services, should be supported in special education while being provided access to general education settings to the greatest extent possible. Labeling students as having a disability and then placing them in a restrictive setting is not a support system (Golds \& Richards, 2012; Linton, 2015).

Special education, if not supporting a student's needs, is solely a restrictive environment. Special education faculty and staff must be reflective of placement of students and examine how instruction is designed for students with disabilities. All students will benefit from access general education curriculum and peers without disabilities, and access must be provided for all students. Obiakor et al. (2012) emphasize that all students with disabilities must have access to "meaningful, rigorous general educa- 
tion curricula; and special education is specifically designed instruction to assist them in maximizing their highest potential" (p. 478). Special education programs that are supportive with high expectations for all students and that include appropriate access to general education settings should be the primary goal for all students with disabilities-a stark contrast to restrictive, secluded environments.

Gatlin and Wilson (2016) explored the experiences of a group of high-achieving Black students placed in special education and found that three overarching themes resulted from the interviews and observations: high expectations, support, and organization. Reflecting on these themes may begin a conversation amongst special education programs and school administration. The Black male students in the study did not feel sufficiently challenged, reported a lack positive peer relationships, and had a misunderstanding of their next steps moving forward after high school, resulting in a high frequency of dropping out of high school. Therefore, it is important to establish high level of expectations, despite the student's label as having a disability. Our goal must be to have Black males students be competitive in society. When students are not placed in academic settings with the intention of the student thriving, they are disenfranchised from receiving opportunities of growth and empowerment (Irvine, 2012). Special education and general education teachers who support students with disabilities must have a variation of teaching strategies for each student's unique learning style, and take into students' perspectives (Fish, 2019).

\section{Conclusion}

With the overrepresentation of Black males in special education, educators in the United States must take action. While this process may be a long process, teachers can be more proactive with their approaches. Teachers, especially White teachers, need to be effectively trained and prepared to teach students from diverse cultural backgrounds (Obiakor, Beachum \& Harris, 2010; Alter, Walker \& Landers, 2013). Instead of continuing to ostracize and create barriers, students from different cultural backgrounds should be celebrated and their differences should be considered and appreciated.

Educators across the United States may lack an understanding of the myriad of often complex factors that lead to the overrepresentation of Black males in special education (Patton, 1998). Therefore, school site and 
school district administrators, must advocate to reverse structural changes that create a divide between diverse students and general education. The societal, cultural, and behavioral context of the American educational system, founded in White middle-class norms, system must be adjusted (Artiles et al., 2010). Education in America can no longer be a system that promotes ostracizing and 'othering,' but rather a system where Black males are supported appropriately.

\section{REFERENCES}

ALTER, P., WALKER, J. \& LANDERS, E. (2013) Teachers' perceptions of students' challenging behavior and the impact of teacher demographics. Education and Treatment of Children. 36 (4). Pp. 51-69.

ARTILES, A. et al. (2010) Justifying and explaining disproportionality, 1968-2008: A critique of underlying views of culture. Exceptional Children. 76 (3). Pp. 279-299.

BEAN, K. (2013) Disproportionality and acting-out behaviors among African American children special education. Child and Adolescent Social Work Journal. 30 (6). Pp. 487-504.

BLANCHETT, W. (2009) A retrospective examination of urban education: From Brown to the resegregation of African Americans in special education-it's time to "go for broke". Urban Education. 44 (4). Pp. 370-388.

CHERNG, H. Y. S. \& HALPIN, P. F. (2016) The importance of minority teachers: Student perceptions of minority versus White teachers. Educational Researcher. 45 (7). Pp. 407-420.

DIZON, F. et al. (2013) School psychologists' reported perspectives on the Larry P. ban and related practices. ProQuest Dissertations and Theses.

FISH, R. E. (2019) Teacher race and racial disparities in special education. Remedial and Special Education. 40 (4). Pp. 213-224.

FORD, D. Y. \& RUSSO, C. J. (2016) Historical and legal overview of special education overrepresentation: Access and equity denied. Multiple Voices for Ethnically Diverse Exceptional Learners. 16 (1). Pp. 50-57.

GATLIN, B. T. \& WILSON, C. L. (2016) Overcoming obstacles: African American students with disabilities achieving academic success. The Journal of Negro Education. 85 (2). Pp. 129-142.

GOLDS, M. E. \& RICHARDS, H. (2012) African American students' experiences in special education programs. Teachers College Record. 26 (1-2). Pp. 143-156.

HARRY, B. \& ANDERSON, M. G. (1994) The disproportionate placement of African American males in special education programs: A critique of the process. Journal of Negro Education. 63 (4). Pp. 602-619.

IRVINE, J. J. (2012) Complex relationships between multicultural education and special education: An African American perspective. Journal of Teacher Education. 63 (4). Pp. 268-274. 
KIM, Y. et al. (2019) Is neighborhood poverty harmful to every child? Neighborhood poverty, family poverty, and behavioral problems among young children. Journal of Community Psychology. 47 (3). Pp. 594-610.

LINTON, K. (2015) Differential ratings of specific behaviors of African American children in special education. Child and Adolescent Social Work Journal. 32 (3). Pp. 229-235.

MANDELL, D. et al. (2008) Ethnic disparities in special education labeling among children with attention-deficit/hyperactivity disorder. Journal of Emotional and Behavioral Disorders. 16 (1). Pp. 42-51.

MORGAN, P. et al. (2017) Are black children disproportionately overrepresented in special education? A best-evidence synthesis. Exceptional Children. 83 (2). Pp. 181-198.

NEAL, I. L. et al. (2003) The effect of African American movement styles on teachers' perceptions and reactions. The Journal of Special Education. 37. Pp. 49-57.

OBIAKOR, F., BEACHUM, F. \& HARRIS, M. (2010) African American students' experiences with special education in Milwaukee public schools. Western Journal of Black Studies. 34 (4). Pp. 425-437.

OBIAKOR, F. E. et al. (2012) Making inclusion work in general education classrooms. Education and Treatment of Children. 35 (3). Pp. 477-490.

PATTON, J. M. (1998) The disproportionate ratings of specific behaviors of African Americans in special education: Looking behind the curtain for understanding and solutions. The Journal of Special Education. 32 (1). Pp. 25-31.

Poverty USA. (2020) The population of poverty USA. [Online] Available from: https:// www.povertyusa.org/facts_[Accessed: 23 June 2020].

ROBINSON, G. C. \& NORTON, P. C. (2019) A decade of disproportionality: a state-level analysis of African American students enrolled in the primary disability category of speech or language impairment. Language, Speech, and Hearing Services in Schools. 50 (2). Pp. 267-282.

SCOTT, A. Q., TRAINOR, A. \& BETTINI, E. (2019) Strategies for recruiting and retaining black male special education teachers. Remedial and Special Education. 40 (4). Pp. 236-247.

SKIBA, R. J. et al. (2016) Risks and consequences of oversimplifying educational inequities: A response to Morgan et al. (2015). Educational Researcher. 45 (3). Pp. 221225.

TALBERT-JOHNSON, C. (2001) The quest for equity: Maintaining African American teachers in special education. Journal of Negro Education. 70 (4). Pp. 286-296.

United States Housing and Urban Development. (2016) Neighborhoods and violent crime. [Online] Available from: https://www.huduser.gov/portal/periodicals/ em/summer16/highlight2.html [Accessed: 23 June 2020].

WOODSON, L. \& HARRIS, S. (2018) Teacher and student demographic variables which predict teacher referrals of males for special education evaluation. Journal of AtRisk Issues. 21 (1). Pp. 32-43. 